Should Free products also be disclosed?
The US is to date far more advanced in the detail to which regulators have applied themselves to this area. This is most probably driven by the larger US economy associated with these types of endorsements (with the most often cited example being that Snoop Dogg reputedly earns around US $\$ 3,000$ a Tweet), but nonetheless demonstrates where the UK may be likely to head in regulatory compliance terms as its own similar industry develops.

And this seems likely as, as the OFT set out its statement, the common driver behind both UK and US regulation is transparency. Although the FTC Act and CPRs differ on a technical level, the rationale of consumer fairness underpins them both. It therefore seems reasonable to assume the practical compliance outcomes will therefore be similar, and 'ad/spon' disclosures may become commonplace in the UK.

An interesting related issue is whether UK bloggers and consumers given free products by brands in the hope that they will try to review them should be required to disclose this. In the US, FTC guidance recommends that brands issuing free products in this way should require recipients to make this clear in any reviews and public comments and should operate an adequate compliance monitoring programme. This is probably also a prudent approach for UK businesses to follow to avoid allegations of offences under the CPRs.

Further issues to consider also include to what extent consumer testimonials and endorsements incentivised by the chance to enter prize draws and contests should only be used by brands when accompanied with appropriate caveats, for example. However, these and other compliance issues will no doubt play out over time.

Tom Harding, Solicitor,

Osborne Clarke

E-mail: tom.harding@ osborneclarke.com

\section{Northern Ireland prize draw rules may be brought into line with rest of UK}

Stephen Groom

Journal of Direct, Data and Digital Marketing Practice (2011) 13, 69-71. doi:10.1057/dddmp.2011.22

Topic: Promotion marketing

Who: The Department for Social Development

Where: Northern Ireland

When: Consultation closes 31 May 2012

Law stated as at: 1 April 2011 


\section{Northern Ireland catches up on prize draws ...}

\section{... and also competitions}

\section{Consultation published}

\section{What happened}

Six years on from 'purchase to enter' prize draws becoming legal in Great Britain (GB) under the Gambling Act 2005 (GA), Northern Ireland (NI) is finally consulting on whether to bring the province's gambling and lottery laws into line with those of the mainland.

Since the coming into force of the GA, promotional prize draws which require a purchase before entering have not breached GB lottery/gambling laws provided the price or rate payable for the purchase does not 'reflect the opportunity to participate in (the promotion)' (Para 2 (c) of Schedule 2 to the GA).

In other words, provided the price or rate payable is normal and has not been artificially inflated to help cover the additional costs of running the promotion, having to make a purchase in order to enter the draw is perfectly legal in GB.

In NI, however, it is the old, unreconstructed lottery laws that still hold sway. This means that unless it comes within limited private society/good cause exemptions, running a purchase to enter prize draw will be a criminal offence as a lottery.

So it came to pass that 'Legal residents of NI may not enter' became common in prize draw rules. Also popular for those determined to be inclusive have been special alternative free entry routes for NI residents. Care is needed here, as it is clear from the writer's experience that certain eagle eyed Ulstermen have been keeping a weather eye on promotions of this type and swooping to take advantage of promotion rules if they see a chance of cashing in.

\section{GB/NI prize competition laws also differ}

Another point of GB/NI difference relates to prize competitions.

GB now allows these provided either:

- no payment is required to participate or

- the level of skill required to win passes a new 'deterrent' test.

In contrast, NI still applies the 'success must depend to a substantial degree on the exercise of skill' test previously applied in GB. This means that any competition will be illegal (regardless of whether it is pay to enter) if the degree of skill required to win does not meet that test.

Now at last, there looks to be at least a chance that all this will soon be history.

The NI Department for Social Development has published a consultation document titled 'Future Regulation of Gambling in Northern Ireland'.

With a deadline for responses of 31 May 2012, the consultation asks for views on whether there might be a change in NI law 'to enable people in NI to participate in prize competitions and free draws on the same basis as those in the rest of the UK'.

The 'free draws' reference is odd because the principal type of prize draw which would be affected by any alignment of NI law with that of 
GB would not be 'free draws' but 'purchase to enter' draws. However, the consultation document does seem to have a full alignment with GB law in this area in its sights. It says:

'In GB, prize competitions and genuine free draws are free from control under the 2005 Act. They can be run for commercial or private gain and can be used as a fun way of offering prizes or promoting a product'.

Why this matters: This is definitely a case of 'better late than never' for UK marketers and their legal advisers, and it will certainly be sighs of relief all round if and when the changes vaunted by this initiative are made. It remains to be seen, however, whether there are still forces at work in the province which will persuade the authorities that the status quo is to be preferred.

Stephen Groom, Head of Marketing and Privacy Law, Osborne Clarke

E-mail: stephen.groom@osborneclarke.com 